\title{
Glomerulonephritis associated with chronic granulomatous disease and systemic lupus erythematosus
}

\author{
C. P. Schmitt ${ }^{1}$, K. Schärer ${ }^{1}$, R. Waldherr ${ }^{2}$, R. A. Seger ${ }^{3}$ and K.-M. Debatin ${ }^{1}$ \\ Departments of ${ }^{1}$ Pediatrics and ${ }^{2}$ Pathology, University of Heidelberg, Germany, and ${ }^{3}$ University Children's Hospital, \\ Zürich, Switzerland
}

\section{Introduction}

Chronic granulomatous disease (CGD) is an inherited immunodeficiency disorder which results from malfunction of the NADPH oxidase system in phagocytic cells. Deficiency of this oxidase, responsible for production of microbicidal oxygen metabolites (e.g. superoxide), leads to reduced killing of catalase-positive bacteria (especially staphylococci) and fungi, and renders affected patients susceptible to recurrent pyogenic infections $[1,2]$. Granuloma formation is induced by unresolved local bacteria containing foci. Sixty per cent of CGD is inherited as a sex-linked trait due to mutations in the gp 91 phox gene which resides at $\mathrm{Xp} \mathrm{21.1.} \mathrm{An} \mathrm{autosomal} \mathrm{recessive} \mathrm{inheritance} \mathrm{is} \mathrm{less}$ frequent [3].

Clinical manifestations start in $80 \%$ before the second birthday [4] and consist of recurrent pyodermia, suppurative lymphadenitis, pneumonia, enteritis, liver abscess, osteomyelitis, and failure to thrive. Aspergillus pneumonia is the leading cause of death [5]. Under continuous prophylaxis using intracellularly active antimicrobials the survival rate at age 20 has increased to $50 \%$ [4]. This report describes a boy with CGD with an unusual systemic and renal complication, namely lupus erythematosus with diffuse proliferative glomerulonephritis.

\section{Case report}

The patient (GD) is the first of two children of nonconsanguineous parents. The mother is prone to infections and, as demonstrated by various leukocyte tests (Table 1), is a carrier of the disease, like the sister. The father is healthy. From the age of 10 weeks the patient developed recurrent episodes of enteritis, cervical and inguinal lymphadenitis, otitis, and pneumonia. Studies of the humoral immune system did not show any abnormalities. At 12 months of age testing

Correspondence and offprint requests to: Prof. Dr Karl Schärer, Division of Pediatric Nephrology, University Children's Hospital, Im Neuenheimer Feld 150, D-69120 Heidelberg, Germany. of peripheral polymorphonuclear neutrophil cells (PMN) revealed a severe deficiency of superoxide anion production, no staining of PMN exposed to nitroblue tetrazolium, and a reduced cytochrome $b$ concentration (Table 1). RFLP analysis showed a mutation at $\mathrm{Xp} 21.1$ (gp 91 phox). However, the precise molecular genetic mechanism still remains unclear. After diagnosis of CGD, prophylaxis with co-trimoxazole and after an additional year with itraconazol was instituted, which reduced the rate of infections. Nevertheless at the age of 3.7 years a severe Candida pneumonia occurred. Incisor teeth were extracted because of severe caries.

In December 1993 at the age of 5.5 years routine examination revealed slight proteinuria and microhaematuria. Some weeks later severe oedema of the eyelids, hands, and ankles, a butterfly rash, and a discrete maculopapular exanthema on the upper and lower extremities developed. On admission in February 1994 we additionally observed reduced motility and tenderness of the right hip, knees, fingers, and ankles. Weight was $20.4 \mathrm{~kg}$, height $123 \mathrm{~cm}$, and blood pressure $110 / 70 \mathrm{mmHg}$. Cervical and submandibular lymph nodes were increased in size but acute infection was absent. Ultrasound examination revealed hepatosplenomegaly and both kidneys appeared large (volume $>97$ th centile) and hyperechogenic. Chest X-ray showed slight interstitial pulmonary infiltration, and echocardiography some thickening of the pericardium. Cranial CT scan was normal.

\section{Laboratory findings}

Blood. Hb $9.2 \mathrm{~g} / \mathrm{dl}$, leukocytes $4500 / \mu \mathrm{l}, \mathrm{CD} 4 / \mathrm{CD} 8$ ratio 0.55 (normal $1-1.4$ ), platelets $40000-100000 / \mu 1$, creatinine $0.5 \mathrm{mg} / \mathrm{dl}$, urea $31 \mathrm{mg} / \mathrm{dl}$, total proteins 5.6 decreasing to $4.7 \mathrm{~g} / \mathrm{dl}$, albumin 32 decreasing to $23 \mathrm{~g} / \mathrm{dl}$, IgA, IgM, and IgG normal, cholesterol $215-345 \mathrm{mg} / \mathrm{dl}$, electrolytes, transaminases and coagulation factors normal.

Serological findings. ANA 1:320 (normal $<1: 40$ ), ds-DNA (ELISA) $2154 \mathrm{IU} / \mathrm{ml}$ (normal $<40 \mathrm{IU} / \mathrm{ml}$ ), ssDNA 98\% (normal <20\%), ENA (nRNP, SSB) positive, ANCA normal. Functional tests of com- 
Table 1. Function tests of peripheral polymorphonuclear neutrophils (PMN)

\begin{tabular}{lccc}
\hline Subject & $\begin{array}{l}\mathrm{O}_{2}^{-} \text {production } \\
\text { (nmol/10 exp 6 PMN/min) }\end{array}$ & $\begin{array}{l}\text { NBT test } \\
\text { (\%positive cells) }\end{array}$ & $\begin{array}{l}\text { Cytochrome b } \\
\text { (pmol/10 exp 6 PMN) }\end{array}$ \\
\hline Patient & 0.031 & 0 & 0.16 \\
Mother & 7.640 & 88 & 4.30 \\
Father & 14.210 & 100 & 5.80 \\
\hline
\end{tabular}

NBT, nitroblue tetrazolium; FACS, fluorescence-activated cell scan

plement: classical pathway $20 \%$, alternative pathway $<20 \%$ (normal $80-120 \%$, haemolytic titration assay), C3 $0.34 \mathrm{mg} / \mathrm{ml}$ (normal 0.5-0.9), C4 $0.04 \mathrm{mg} / \mathrm{ml}$ (normal 0.1-0.4), C3 Nef negative. Cardiolipin $35 \mathrm{U} / \mathrm{ml}$ (normal $<25$ ). Viral and fungal antibodies within normal ranges.

Urine. Proteinuria $3.7-6.3 \mathrm{~g} / \mathrm{m}^{2} / 24 \mathrm{~h}$ (Coumassie method), SDS-PAGE 93\% albumin, 2\% lowmolecular, 5\% high-molecular proteins, erythrocytes up to $>500 / \mu \mathrm{l}$, leukocytes $25-60 / \mu \mathrm{l}$, creatinine clearance $88 \mathrm{ml} / \mathrm{min} / 1.73 \mathrm{~m}^{2}$.

Renal biopsy. Diffuse proliferative glomerulonephritis was found in 25 glomeruli with glomerular basement membrane thickening and segmental subendothelial deposits (MPGN-like). PAS staining demonstrated occasional adhesions and immunofluorescence granular deposits of IgA, IgG, IgM, C3, and C3d in the mesangium and along glomerular basement membranes in subendothelial and subepithelial locations.

\section{Clinical course}

The patient was treated with prednisone $60 \mathrm{mg} / \mathrm{m}^{2} /$ day for 7 weeks followed by decreasing doses on alternate days (Figure 1). In addition, he received frusemide, nifedipine, and atenolol because of rising blood pressure. Antibiotic prophylaxis was continued with rifampicin $(15 \mathrm{mg} / \mathrm{kg} /$ day $)$, itraconazole $(5-10 \mathrm{mg} / \mathrm{kg} /$ day $)$ and colistin $\left(3 \times 10^{6} \mathrm{U} /\right.$ day $)$. The peripheral oedema and the other clinical symptoms disappeared within a few weeks, the general state improved, and somatic development remained normal. Intercurrent otitis media and lymphadenitis were successfully treated with ampicillin and cefuroxime. Two episodes of upper airway infection subsided spontaneously. No clinical or serological signs of fungal infection appeared.

After 8 months of steroid treatment proteinuria decreased to $0.3-0.9 \mathrm{~g} / \mathrm{m}^{2} /$ day and serum albumin levels rose to $4.2 \mathrm{~g} / \mathrm{l}$. Renal function remained normal (serum creatinine $0.3 \mathrm{mg} / \mathrm{dl}$, urea $22 \mathrm{mg} / \mathrm{dl}$, creatinine clearance $\left.166 \mathrm{ml} / \mathrm{min} / 1.73 \mathrm{~m}^{2}\right) ; \mathrm{Hb}$ increased to $13.2 \mathrm{~g} / \mathrm{dl}$, ANA titres decreased to $1: 80$ and ds-DNA to $282 \mathrm{IU} / \mathrm{ml}$.

\section{Discussion}

Involvement of the urinary tract has been reported in $38 \%$ of patients with CGD. It consists mainly of urinary tract infections and obstructions due to granu-

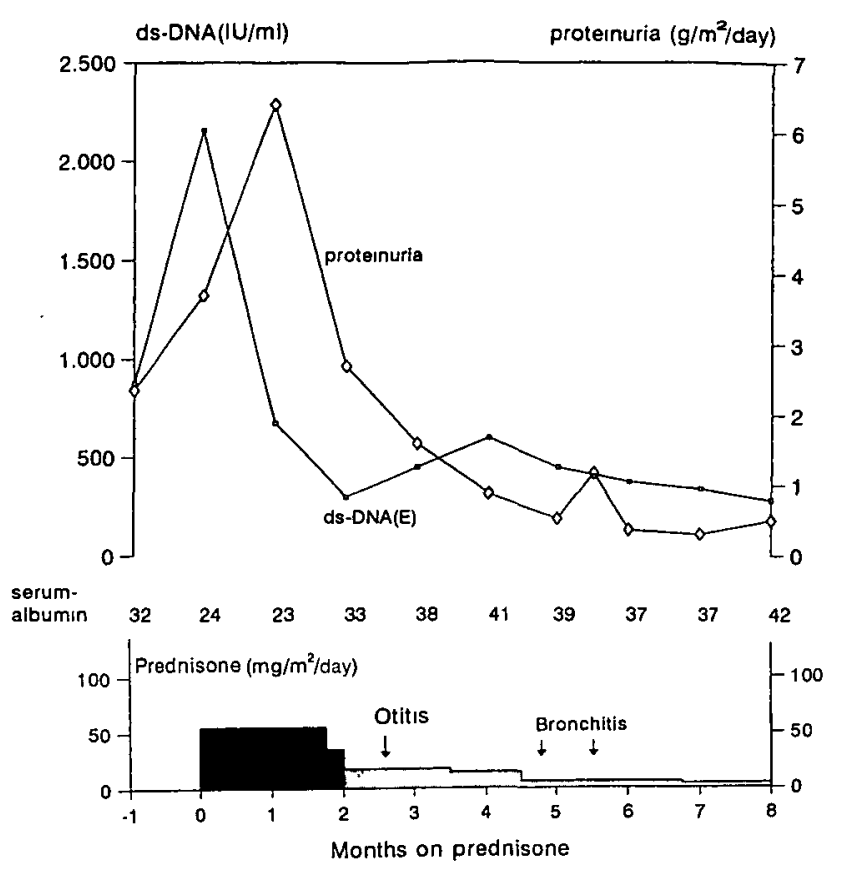

Fig. 1. Course of proteinuria ( $\mathrm{g} / \mathrm{m}^{2}$ body surface/day), serum albumin $(\mathrm{g} / \mathrm{l})$ and double-stranded $(\mathrm{ds})$ DNA I month before and during 8 months on prednisone therapy. Daily $\square$ Every other day.

loma formation, eventually leading to strictures and renal abscesses [6]. In contrast, glomerular lesions have been described in only six cases of CGD aged 3-18 years [6-10]. The initial features were usually mild, consisting of proteinuria and microscopic haematuria. Renal function was decreased in four cases; two patients required haemodialysis. Our patient is the only one who developed overt nephrotic syndrome with oedema. One further patient reported by Manzi et al. [10] exhibited a similar clinical course, also associated with signs and symptoms of SLE.

SLE is a rare disease in small children. According to Cameron et al. only 130 children below age 10 with SLE have been reported in the literature; $80 \%$ of them initially presented with renal symptoms and $50 \%$ developed nephrotic syndrome. Under treatment with corticosteroids and cytotoxic agents the survival rate in this age group has improved to $85 \%$ after 10 years [11].

Manifestations of lupus have repeatedly been noted in the family history of CGD patients. Therefore the association of SLE and CGD appears to be causally related. According to Manzi et al. [10], 22 female 


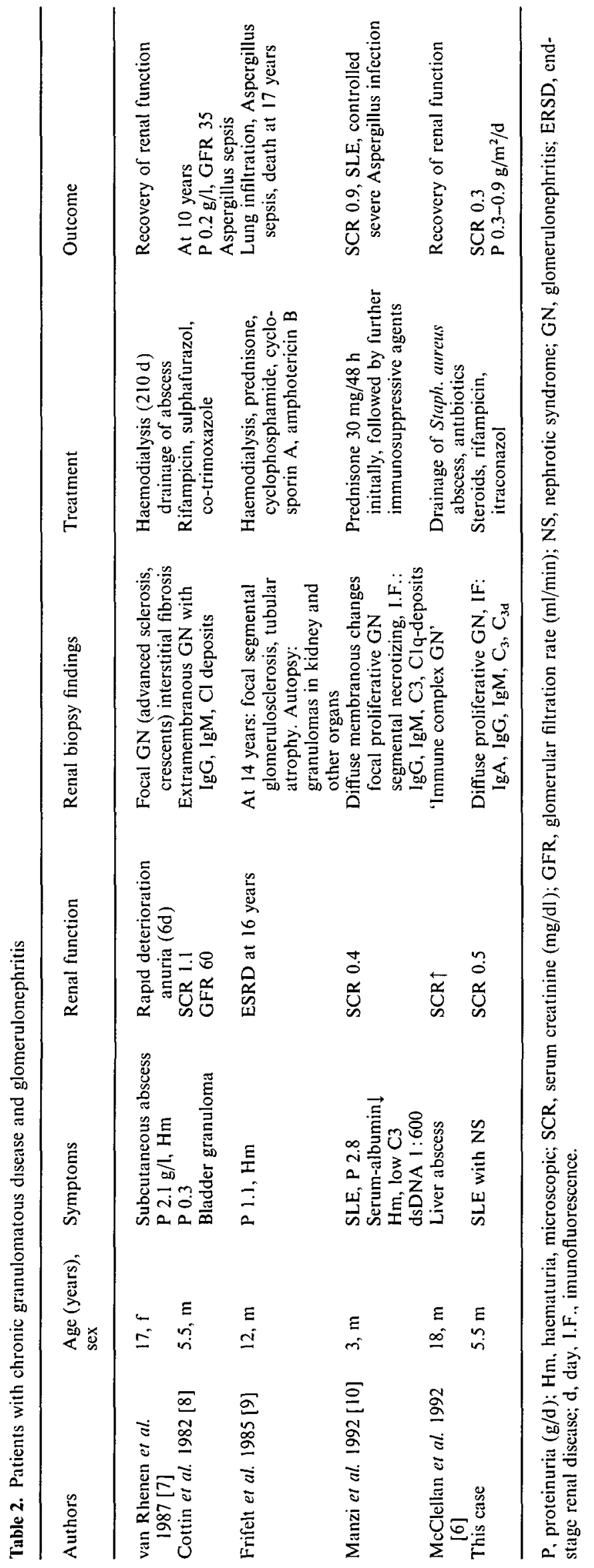


carriers of CGD had clinical features consistent with lupus-like lesions, such as discoid lupus, photosensitivity, or aphthous stomatitis. The serological findings in these carriers were negative with two exceptions: one with discoid lupus and positive ANA-titres [12] and one with clinical symptoms of SLE but without renal manifestations [13]. In another carrier transient glomerulonephritis was noted during childhood [14]. In addition, four CGD patients were reported to have discoid lupus without dsDNA antibodies [15-17].

The pathoanatomical features observed in the six cases of CGD reported with glomerular lesions were variable (Table 2). Besides focal proliferative and sclerotic lesions, diffuse glomerular involvement was observed as in our case. Granulomas of the kidney were noted in only one case [9]. Other forms of renal granulomatous disease seem to be excluded. The presence of diffuse immunoglobulin and complement deposits in kidney or skin biopsies $[6,7,10]$ suggests an immune-complex nephritis. This is supported by rising titres of circulating immune complexes, as were found in another patient [8].

The association of CGD with glomerular lesions and SLE may be the result of an exaggerated inflammatory response observed in this disorder. Due to the defective phagocytes, microbial persistence may lead to chronic antigen stimulation of the immune system. Studies by Sato et al. [18] in renal biopsies of patients with IgA nephropathy suggest that phagocytic dysfunction of PMN may cause mesangial deposition of immune complexes. The repeated exposure to antigens from damaged host cells in CGD could result in overproduction of autoantibodies. In addition, impaired clearance of antigens or soluble immune complexes due to overload of the reticuloendothelial system might cause renal damage. The development of autoimmune phenomena including SLE also occurs with other hereditary defects of host defence mechanisms or from acquired immune deficiency syndromes [19-21]. Our hypothesis is supported by animal experiments that showed immune complexes binding to glomerular cells, stimulating superoxide release [22].

The outcome of CGD patients associated with glomerulonephritis varied (Table 2). The case described by van $R$ henen et al. [7] deteriorated rapidly and reached end-stage renal disease within 4 months but recovered, at least partly, after 7 months on dialysis treatment. A partial recovery was also reported in the other cases except in that of Frifelt et al. [9] who died after 15 months on dialysis. The immunosuppressive treatment applied in that case was repeatedly followed by pulmonary infiltrations due to Aspergillus sepsis and was therefore discontinued. The case reported by Manzi et al. [10], also associated with SLE, was treated with steroids and showed a prolonged course, complicated by multiple Aspergillus and other infections involving the CNS; for the last 4 years this patient was without signs of SLE and the proteinuria seems to be well controlled without immunosuppressive therapy (personal communication A. H. Urbach).

We were encouraged to use steroids because their administration was successful and well tolerated in CGD patients with obstructions of the gastrointestinal or urinary tract secondary to persistent granuloma formation. However, medication has been given in lower doses and for limited time [6,23]. In our case steroid treatment was well tolerated and induced a clinical and serological remission of SLE and renal symptoms, with a decline of proteinuria below $1 \mathrm{~g} / \mathrm{m}^{2} /$ day and stable GFR. The mild course of intercurrent infections we observed during steroid therapy may be ascribed to the relatively high number of residual cytochrome-b-positive $\mathrm{PMN}$ in our patient ( $3 \%$ versus none in most cases of $X$-linked CGD). Lifelong chemoprophylaxis against infections seems to be important for the outcome [2]. Rifampicin was chosen because co-trimoxazole had previously induced thrombocytopenia; in addition, it may be a potential cause of discoid lupus. Itraconazol was added as a potent oral antifungal agent which is also active against Aspergillus. In a recent prospective randomized trial interferon gamma was found to reduce the frequency of severe infections [25,26]. This drug was avoided because of its risk of inducing SLE [27] and previous applications in our case provoked fever.

In conclusion CGD must be regarded as a potential cause of chronic glomerulonephritis. Children and young adults with repeated purulent infections who present with unexplained proteinuria should be screened for this disorder. The combination of CGD with SLE reported here strongly suggests an immune pathogenesis. An optimal treatment schedule needs to be worked out for similar cases.

\section{References}

1. Hitzig WH, Weber C. Die progressive septische Granulomatose. Ergebn Inn Med Kinderheilk 1980; 44: 37-72

2. Seger R, Berthat F, Hossle JP. Chronic granulomatous disease. Allergy Immunol 1992; 3: 1-10

3. Smith RM and Curnette JT. Molecular basis of chronic granulomatous disease. Blood 1991; 77: 673-686

4. Finn A, Hadzic N, Morgan G, Strobel S, Levinsky RJ. Prognosis of chronic granulomatous disease. Arch Dis Child 1990; 65: 942-945

5. Cohen MB, Isturiz RE, Malech HL et al. Fungal infection in chronic granulomatous disease. Am J Med 1981; 71: 59-62

6. McClellan MW, Malech $\mathrm{H}$, Berman A et al. The urological manifestations of chronic granulomatous disease. J Urol 1992; 147: $1314-1318$

7. Van Rhenen DJ, Koolen MI, Feltkamp-Vroom TM, Weening RS. Immune complex glomerulonephritis in chronic granulomatous disease. Acta Med Scand 1979; 206: 233-237

8. Cottin X, Chopard P, Cotton JB, Larbre F. Glomerulonéphrite extra-membraneuse au cours d'une granulomatose septique chronique. Pediatrie 1982; 37: 299-304

9. Frifelt JJ, Schönheyder H, Valerius NH, Starklint H. Chronic granulomatous disease with chronic glomerulonephritis. Acta Paediatr Scand 1985; 74: 152-157

10. Manzi S, Urbach AH, McCune AB et al. Systemic lupus erythematosus in a boy with chronic granulomatous disease: case report and review of the literature. Arthritis Rheum 1991; 34: $101-105$

11. Cameron JS. Lupus nephritis in childhood and adolescence Pediatr Nephrol 1994; 8: 230-249

12. Barton LL, Johnson CR. Discoid lupus erythematosus and 
X-linked chronic granulomatous disease. Pediatr Dermatol 1986; 3: $376-379$

13. Schaller J. Illness resembling lupus erythematosus in mothers of boys with chronic granulomatous disease. Ann Intern Med 1972; 76: $747-750$

14. Brandrup F, Koch C, Petri M, Schiodt M, Johansen KS. Discoid lupus erythematosus-like lesions and stomatitis in female carriers of X-linked chronic granulomatous disease. Br J Dermatol 1981; 104: 495-505

15. Gallin JI, Buescher ES, Seligmann BE, Nath J, Gaither T, Katz P. Recent advances in chronic granulomatous disease. Ann Intern Med 1983; 99: 657-674

16. Stalder JF, Dreno B, Bureau B, Hakim J. Discoid lupus erythematosus-like skin lesions in an autosomal form of chronic granulomatous disease. $B r J$ Dermatol 1986; 114: 251-254

17. Strate $M$, Brandrup F, Wang $P$. Discoid lupus erythematosuslike skin lesions in a patient with autosomal recessive chronic granulomatous disease. Clin Genet 1986; 30: 184-190

18. Sato M, Kinugasa E, Ideura T, Koshikawa S. Phagocytic activity of polymorphonuclear leucocytes in patients with IgA nephropathy. Clin Nephrol 1983; 19: 166-171

19. Schopfer K, Feldges A, Baerlocher K, Parisot RF, Wilhelm JA, Matter L. Systemic lupus erythematosus in Staphylococcus aureus hyperimmunoglobulinaemia E syndrome. $\mathrm{Br}$ Med J 1983; 287: $524-526$
20. Winchester R. Immunodeficiency and arthritis. Curr Opin Rheumatol 1989; 1: 199-204

21. Berman A, Espinoza LR, Aguilar JL et al. Rheumatic manifestations of human immunodeficiency virus infection. $\mathrm{Am} J \mathrm{Med}$ 1988; 85: 59-64

22. Sedor JR, Carey SW, Emancipator SN. Immune complexes bind to cultured rat glomerular mesangial cells to stimulate superoxide release. Evidence for an Fc receptor. I Immunol 1987; 138: 3751-3757

23. Chin TW, Stiehm ER, Falloon J, Gallin JI. Corticosteroids in treatment of obstructive lesions of chronic granulomatous disease. J Pediatr 1987; 111: 349-352

24. Seger R, Erekowitz RA. Treatment of chronic granulomatous disease. Immunodeficiency 1994; 5: 113-130

25. The International Chronic Granulomatous Disease Cooperative Study Group. A controlled trial of interferon gamma to prevent infections in chronic granulomatous disease. N Engl J Med 1991; 324: $509-516$

26. Mouy R, Seger R, Bourquin JP et al. Interferon gamma for chronic granulomatous disease. $N$ Engl J Med 1991; 325: 509-516

27. Graninger WB, Hassfeld W, Pesau BB, Machold KP, Zielinski CC, Smolen JS. Induction of systemic lupus erythematosus by interferon gamma in a patient with rheumatoid arthritis. $J$ Rheumatol 1991; 18: 1621-1622

Received for publication: 18.11 .94

Accepted in revised form: 12.95 